EGU2020-21141, updated on 05 May 2020

https://doi.org/10.5194/egusphere-egu2020-21141

EGU General Assembly 2020

(c) Author(s) 2020. This work is distributed under

the Creative Commons Attribution 4.0 License.

\title{
Microbial role in N2O-NO2 production and CH4 oxidation under active hypogenic settings
}

Tamara Martin-Pozas ${ }^{1}$, Soledad Cuezva ${ }^{2}$, Valme Jurado ${ }^{3}$, Raul Perez-Lopez ${ }^{4}$, Cesareo Saiz-jimenez ${ }^{3}$, Jose Maria Calaforra ${ }^{5}$, Sergio Sanchez-Moral' ${ }^{1}$, and Angel Fernandez-Cortes ${ }^{5}$

${ }^{1}$ MNCN-CSIC, Geology, Madrid, Spain

${ }^{2}$ University of Antwerp, Department of Biology, Research group Plants and Ecosystems, Antwerp, Belgium

${ }^{3}$ IRNAS-CSIC, Department of Agrochemistry, Environmental Microbiology and Soil Conservation, Sevilla, Spain

${ }^{4}$ Geological and Mining Institute of Spain, Geological Hazards Area Department of Geoscience Research and Prospective, Madrid, Spain

${ }^{5}$ University of Almeria, Research group Water Resources and Environmental Geology, Almeria, Spain

The hydrothermal caves linked to active faulting have subterranean atmospheres with a distinctive gaseous composition containing deep endogenous gases, such as carbon dioxide, methane and nitrogen oxides (NOx). Ascending fluids through associated near-surface hydrothermal processes can mobilize endogenous gases into the Critical Zone and, ultimately, to the lower troposphere.

Nitrogen oxides are polluting gases and can have adverse effects on human health, especially inhaled NO2. They also catalyse ozone (03) production in the lower layers of the atmosphere and the greenhouse effect, when they react with volatile organic compounds. The largest source of NOx emissions is anthropogenic. The rest is produced naturally by microbial processes in soil and water, by lightning, volcanic activity, storms, etc. Production of $\mathrm{N} 2 \mathrm{O}$ and NO2 is associated with soil and other active-geothermal ecosystems, far less is known about the sources and sinks of these gases within subterranean locations. Here, we report high N2O and NO2 concentrations detected along a hypogenic system associated with an active faulting (Vapour Cave, southern Spain), which enables direct gas exchange with the low-atmosphere. These anomalous concentrations of N2O and, NO2 are about ten and five times higher than the typical atmospheric background, respectively.

Gaseous composition analyses of subterranean atmosphere were conducted by high precision field-deployable CRDS and FTIR spectrometers for measuring in situ the target tracer gases (NO2, $\mathrm{N} 2 \mathrm{O}, \mathrm{CH} 4, \mathrm{CO} 2$ ) and $\delta 13 \mathrm{C}$ of both carbon-GHGs. DNA extraction, sequencing and phylogenetic analyses were conducted to characterize the microbial community of cave sediments. The results showed that $\mathrm{N} 2 \mathrm{O}$ and $\mathrm{NO} 2$ emission depends on the activity of nitrification by ammonia oxidizing microorganisms (such as members of the family Nitrosomonadaceae and phylum Thaumarchaeota) and/or as a result of incomplete denitrification by heterotrophic denitrifying bacteria (such as Bacillus, Acinetobacter and Cupriavidus) from this hydrothermal and hypoxic ecosystem.

On the other hand, $\mathrm{CH} 4$ concentrations and $813 \mathrm{CH} 4$ vary along the cave (with the deep), in deepest cave locations $\mathrm{CH} 4$ values are higher with lighter $813 \mathrm{C}$ values in comparison with the 
more superficial areas, which indicates a deep endogenous origin of methane. However, in areas near the entrance we observe lower concentrations of methane and heavier $\delta 13 \mathrm{C}$ values $(\mathrm{CH} 4<1$ ppm and $\delta 13 \mathrm{C}$ close to $-30 \%$ ), as a result of methane oxidation by denitrifying methanotrophs of the NC10 phylum during gas migration from the deepest areas to the surface.

These new findings reveal the sourcing of these nitrogenous gases into the upper vadose zone of a hypogenic/geothermal ecosystem, and its potential release to the lower troposphere. A better understanding of biogeochemical processes controlling the production of nitrogenous gases in subterranean environments will be useful to identify and characterize new possible sources, reservoirs and sinks of greenhouse gases $(\mathrm{CO} 2, \mathrm{CH} 4, \mathrm{~N} 2 \mathrm{O}$ and NOx) in order to calculate more accurately the budgets and for the design of new mitigation strategies of these gases. 